\title{
Curing characteristics, mechanical and thermal properties of reclaimed ground tire rubber cured with various vulcanizing systems
}

\author{
Krzysztof Formela • Dominik Wąsowicz • \\ Magdalena Formela $\cdot$ Aleksander Hejna \\ Józef Haponiuk
}

Received: 27 August 2014 / Accepted: 24 February 2015 / Published online: 10 March 2015

(C) The Author(s) 2015. This article is published with open access at Springerlink.com

\begin{abstract}
Ground tire rubber was thermo-mechanical reclaimed at $120{ }^{\circ} \mathrm{C}$ using a co-rotating twin screw extruder. The effect of vulcanizing system type on curing characteristics, static mechanical properties (tensile strength, elongation-at-break, hardness and resilience), dynamic mechanical properties and thermal properties of reclaimed ground tire rubber was investigated. Reclaimed rubber was cured using different types of vulcanization accelerators (MBT, TBBS, TMTD, DPG, CBS) commonly used in industry. Two ratios of vulcanization accelerator/sulfur [2:1 as conventional system and 1:2 as effective system (EV)] were used. Presented results indicate that static and dynamic mechanical properties of revulcanized reclaimed rubber depend strongly on vulcanizing system type. The highest cross-link density showed samples cured with TMTD which corresponds to $\Delta M$ values, glass transition temperature and equilibrium swelling degree of these products. The best processing and mechanical properties were estimated for revulcanized reclaimed rubber cured with conventional vulcanizing system based on TBBS and CBS accelerators. These results showed that reclaimed rubber obtained via low temperature extrusion is suitable for application in rubber compounds.
\end{abstract}

Keywords Reclaimed ground tire rubber - Revulcanized reclaimed rubber $\cdot$ Cross-link density $\cdot$ Vulcanization accelerator

K. Formela ( $₫)$ · D. Wąsowicz · M. Formela · A. Hejna ·

J. Haponiuk

Department of Polymer Technology, Faculty of Chemistry, Gdańsk University of Technology, G. Narutowicza Str. 11/12, 80-233 Gdańsk, Poland

e-mail: kformela.ktp@gmail.com; krzysztof.formela@pg.gda.pl

\section{Introduction}

Searching for new methods of used tires recycling is a widespread topic of research conducted by industries and scientific centers all over the world [1-3]. Ground tire rubber (GTR) and reclaimed rubber are commonly used in rubber industry as substitutes of fillers and elastomers in rubber compounds. Ongoing research aims at optimization of rubber compounds containing GTR/reclaimed rubber with simultaneous maintenance of properties of resulting products. One of the simplest and economically beneficial methods of the enhancement of rubber properties is proper selection of curing system and conditions of vulcanization. These conditions significantly affect the cross-link density of vulcanizates, which to a large degree controls their mechanical and thermal properties $[4,5]$.

Rattanasom et al. [6] investigated the effect of vulcanizing systems on mechanical properties of natural rubber (NR) vulcanizates containing 10-50 phr of reclaimed rubber. At this research two types of curing systems were used: conventional $(\mathrm{CV})$ and effective $(\mathrm{EV})$. Authors attained better mechanical properties for products obtained from compounds with conventional vulcanizing system.

Kim et al. [7, 8] characterized the influence of curing system on morphology and properties of rubber compounds containing GTR particles. Obtained results confirmed that type of vulcanizing system has strong impact on curing characteristics and mechanical properties of vulcanizates filled with GTR. Low mechanical properties of vulcanizates containing GTR was the result of two main factors: weak interfacial elastomer-filler interactions and change in cross-link density of vulcanizates filled with GTR.

Ismail et al. [9-11] investigated the influence of the vulcanizing system on the properties of rubber blends based on natural rubber/recycled EPDM (ethylene-propylene-diene 
Table 1 Characteristics of reclaimed rubber obtained by different methods [23-28]

\begin{tabular}{|c|c|c|c|c|c|c|}
\hline $\begin{array}{l}\text { GTR particle } \\
\text { size }(\mathrm{mm})\end{array}$ & Reclaiming method & Curing conditions & $\begin{array}{l}\text { Vulcanizing sys- } \\
\text { tem (phr) }\end{array}$ & $\begin{array}{l}\text { Tensile strength } \\
(\mathrm{MPa})\end{array}$ & $\begin{array}{l}\text { Elongation-at- } \\
\text { break }(\%)\end{array}$ & Reference no. \\
\hline 0.50 & $\begin{array}{l}\text { Grinding, ultrasonically } \\
\text { treated, ozone/ultra- } \\
\text { sonically treated }\end{array}$ & $\begin{array}{l}T=150^{\circ} \mathrm{C} \\
p=- \\
t=15 \mathrm{~min}\end{array}$ & - & $3.2-5.1$ & $135-160$ & {$[23]$} \\
\hline 0.05 & Microbial desulfurization & $\begin{array}{l}T=150^{\circ} \mathrm{C} \\
p=15 \mathrm{MPa} \\
t=-\end{array}$ & - & 3.3 & 191 & {$[24]$} \\
\hline 0.25 & $\begin{array}{l}\text { Shearing in pan mill } \\
\text { mechanochemical } \\
\text { reactor. }\end{array}$ & $\begin{array}{l}T=150^{\circ} \mathrm{C} \\
p=10 \mathrm{MPa} \\
t=15 \mathrm{~min}\end{array}$ & $\begin{array}{l}\mathrm{ZnO} / \text { stearic acid/ } \\
\text { CBS/sulfur: } \\
\text { 2.0/1.0/0.5/1.5 }\end{array}$ & $4.2-8.4$ & 109-202 & {$[25]$} \\
\hline 0.60 & $\begin{array}{l}\text { Thermomechanical } \\
\text { co-rotating twin screw } \\
\text { extruder }\end{array}$ & $\begin{array}{l}T=150^{\circ} \mathrm{C} \\
p=10 \mathrm{MPa} \\
t=10 \mathrm{~min}\end{array}$ & $\begin{array}{l}\mathrm{ZnO} / \text { stearic acid/ } \\
\text { TBBS/sulfur: } \\
\text { 2.5/0.4/0.8/1.2 }\end{array}$ & $5.6-12.5$ & $337-353$ & {$[26]$} \\
\hline 0.19 & $\begin{array}{l}\text { Thermomechanical in } \\
\text { counter-rotating twin } \\
\text { screw extruder }\end{array}$ & $\begin{array}{l}T=150{ }^{\circ} \mathrm{C} \\
p=- \\
t=\text { according } \\
\quad \text { Monsanto Rheometer }\end{array}$ & $\begin{array}{l}\mathrm{ZnO} / \text { stearic acid/ } \\
\text { MBT/sulfur: } \\
\text { 5.0/2.5/1.0/1.5 }\end{array}$ & $2.6-4.7$ & $164-230$ & [27] \\
\hline 1.50 & $\begin{array}{l}\text { Thermomechanical in } \\
\text { counter and co-rotating } \\
\text { twin screw extruder }\end{array}$ & $\begin{array}{l}T=150{ }^{\circ} \mathrm{C} \\
p=4.9 \mathrm{MPa} \\
t=\text { according to } \\
\quad \text { Monsanto Rheometer }\end{array}$ & $\begin{array}{l}\mathrm{ZnO} / \text { stearic acid/ } \\
\text { TBBS/sulfur: } \\
\text { 2.5/1.0/0.35/1.5 }\end{array}$ & $3.3-6.5$ & $114-180$ & [28] \\
\hline
\end{tabular}

monomer). Presented results confirmed the significant influence of vulcanizing system (especially type of vulcanization accelerator) on curing characteristics, mechanical and thermal properties of the obtained vulcanizates.

Gibala et al. [12-14] demonstrated that vulcanization accelerator's residues present in ground rubber may affect on curing characteristics and mechanical properties of rubber compounds filled with ground rubber. Obtained results suggest that accelerator's residue migration occurred from ground rubber to elastomer matrix; on the other hand, the migration of sulfur occurred in opposite direction.

Guzmán et al. [15] discussed the possibility of the use of GTR as vulcanization activator in order to reduce the content of zinc oxide in rubber compounds. Authors recommended further research on interactions between additives present in the GTR particles and in the rubber compounds.

Vulcanization accelerators are applied as reclaiming/ devulcanization agents, as they have effect on the process of breakdown of cross-links and on secondary vulcanization of resulting reclaimed rubber $[16,17]$. Widely promoted in the 90s of last century product from STI-K Polymers American with trade name deLink ${ }^{\circledR}[18,19]$ was a mixture of zinc dithiophosphate with suitable vulcanization accelerators.

Correlation between vulcanizing system type and properties of reclaimed rubber is crucial, especially in case of low-cost products based on waste rubber. Therefore, development of research projects focused on new methods of reclamation of GTR [20-22] requires better understanding of the impact of vulcanizing systems on the properties of the obtained products.
Mechanical properties of vulcanized reclaimed rubber prepared in different conditions are shown in Table 1. Presented data suggested that method and parameters of reclamation of rubber, in particular the composition and particle size of GTR, influenced the quality of the products. Other important factors are: curing conditions (temperature, pressure, time) and the character of vulcanizing system. Consideration of parameters presented above is necessary for comparison of results published by different research groups.

The present state of knowledge shows the effect of vulcanization accelerators on properties of rubber compounds containing ground rubber/reclaimed rubber. However, it is hard to find any published data about influence of curing system, particularly accelerator type and accelerator/sulfur ratio on properties of reclaimed rubber. Optimization of curing system improved processing and mechanical properties of revulcanized rubber (vulcanized reclaimed rubber) which affected on quality and price of the final product.

In the presented work the effects of vulcanizing system efficiency on the curing process, thermal, static mechanical properties (tensile strength, elongation-at-break, hardness, resilience, and abrasion resistance) and dynamic mechanical properties of reclaimed GTR were determined. For this study five types of commonly used vulcanization accelerators were used. Furthermore, for better understanding of correlation between vulcanizing system efficiency and properties of reclaimed rubber, two ratios of vulcanization accelerator/sulfur were used: conventional vulcanizing system (CV) with accelerator/sulfur ratio 1:2 and efficient vulcanizing system (EV) with accelerator/sulfur ratio 2:1. 


\section{Experimental}

\section{Materials}

Ground tire rubber obtained by ambient grinding of used tires (combination of passenger car and truck tires in mass ratio 50:50) with particles size below $0.8 \mathrm{~mm}$, produced by Orzeł S.A. (Poland) was used for the research. Particle size distribution of GTR particles is shown in the Fig. 1.

Ground tire rubber was thermo-mechanically reclaimed using a co-rotating twin screw extruder EHP $2 \times 20$ from Zamak (Poland) furnished with eleven heating/cooling zones. Screw diameter of the extruder was $20 \mathrm{~mm}$ and an $L / d$ ratio was 40 . Barrel of the extruder was heated to $120{ }^{\circ} \mathrm{C}$ in all zones, while rotating speed of screws was $600 \mathrm{rpm}$. Throughput of GTR during reclaiming was $1.5 \mathrm{~kg} / \mathrm{h}$. Lower temperature during reclaiming prevented secondary cross-linking of the reclaimed GTR and increased the shearing efficiency of the GTR. Moreover, reclaiming of GTR conducted at lower temperature reduced cost of energy and significantly decreases the amount of gases and low molecular degradation products (i.e., accelerators and plasticizers) generated during the process [29].

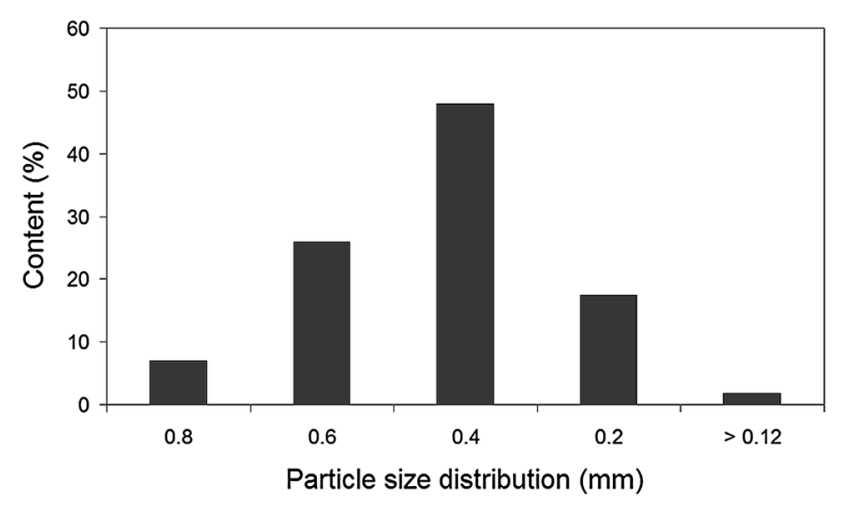

Fig. 1 Ground tire rubber (GTR) particles size distribution
The appearance of GTR before and after reclaiming is shown in Fig. 2. Sol fraction content (extraction with toluene conducted at room temperature for $72 \mathrm{~h}$ ) of GTR was $4.1 \%$ and for reclaimed GTR was $10.7 \%$. Changes of sol fraction content confirmed the reclaiming of GTR. Vulcanization agents with technical purity were supplied by Standard Sp. z o.o. (Poland).

\section{Sample preparation}

Obtained reclaimed rubber was mixed with particular vulcanizing system using two roll mills from Buzuluk (Czech Republic). Formulation of investigated rubber compounds is shown in Table 2. Samples were vulcanized at $150{ }^{\circ} \mathrm{C}$, under the pressure of $4.9 \mathrm{MPa}$, according to estimated optimum vulcanization time.

Chemical structures and physical properties of used vulcanization accelerators are shown in the Scheme 1 and Table 3, respectively.

\section{Measurements}

Vulcanization process was characterized according to PN-ISO 3417 at $150{ }^{\circ} \mathrm{C}$, using a Monsanto R100S (USA) rheometer with oscillating rotor. Oscillation angle was $3^{\circ}$ and torque range $0-100 \mathrm{dNm}$. Cure rate index (CRI) values were calculated in accordance with the Eq. (1) [30]:

$\mathrm{CRI}=\frac{100}{t_{90}-t_{2}}$

where, $t_{90}$ is optimum vulcanization time (min) and $t_{2}$ is scorch time (min).

To determine the aging resistance of vulcanizates at elevated temperatures, $R_{300}$ parameter was determined [31]. $R_{300}$ is the percentage reversion degree after a period of $300 \mathrm{~s} \mathrm{cal}-$ culated from the time of reaching maximum value of torque $M_{\mathrm{H}} \cdot R_{300}$ was calculated in accordance with the Eq. (2):
Fig. 2 Appearance of ground tire rubber (sol fraction: $4.1 \%$ ) before (a) and after (b) reclaiming (sol fraction: $10.7 \%$ )
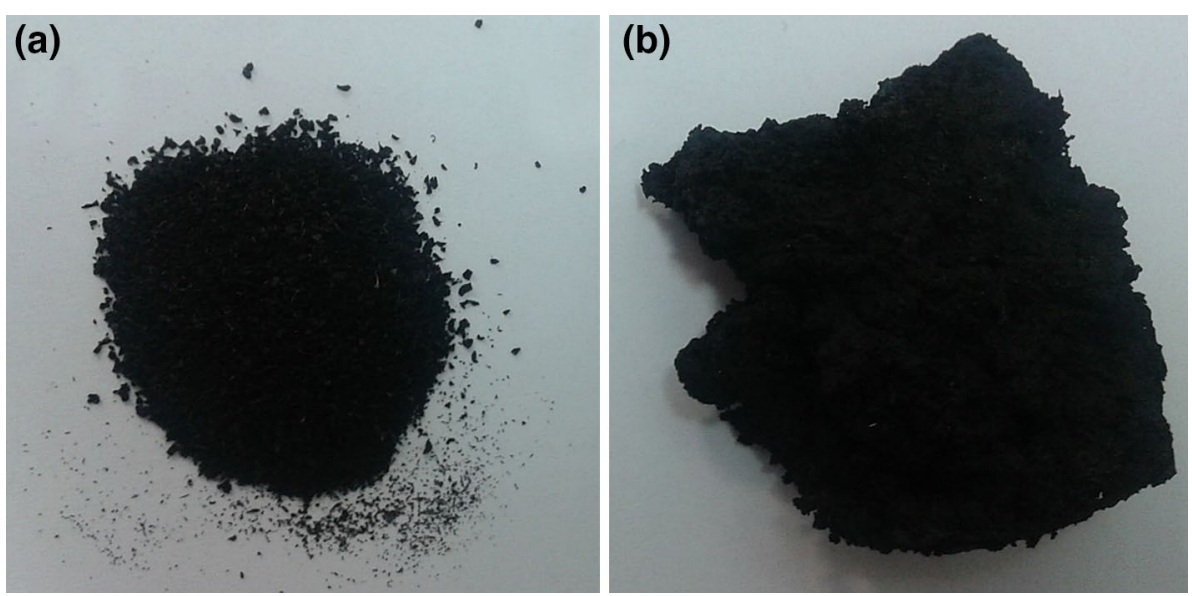
$R_{300}=\frac{M_{\mathrm{H}}-M_{300 \mathrm{~s}}}{M_{\mathrm{H}}} \times 100$

where, $M_{\mathrm{H}}$ is maximum torque and $M_{300 \mathrm{~s}}$ is torque estimated at $300 \mathrm{~s}$ after occurring of maximum torque.

The tensile strength, elongation-at-break, moduli $M_{50}$ and $M_{100}$ (stresses at 50 and $100 \%$ of elongation, respectively) were estimated in accordance with PN-ISO 37. Tensile tests were performed on the a Zwick Z020 (Germany) machine at a constant speed of $500 \mathrm{~mm} / \mathrm{min}$. Shore hardness type A was estimated using a Zwick 3130 (Germany) durometer in accordance with ISO 7619-1. Rebound resilience was measured with a Schob Pendulum Rebound tester (Gibitre Instruments, Italy) in accordance with ISO 4662. Abrasion resistance was measured according to ISO 4649 using a Gibitre (Italy) abrasion tester. Abrasion resistance was calculated in accordance with the Eq. (3):

$A=\frac{m_{1}-m_{2}}{\rho} \times \frac{1}{\eta} \times 1000$

where, $A$ is abrasion resistance $\left(\mathrm{mm}^{3}\right), m_{1}$ is initial mass of sample $(\mathrm{g}), m_{2}$ is mass of sample after abrasion test $(\mathrm{g}), \rho$

Table 2 Formulation of compounds based on reclaimed rubber

\begin{tabular}{ll}
\hline Component & Content $(\mathrm{phr})$ \\
\hline Reclaimed rubber & 100 \\
ZnO & 3 \\
Stearic acid & 1 \\
Accelerator & Variable \\
Sulfur & Variable \\
\hline
\end{tabular}

is density of tested sample $\left(\mathrm{g} / \mathrm{cm}^{3}\right)$ and $\eta$ is coefficient of abrasion intensity determined for reference vulcanizate.

Dynamic mechanical analysis was performed using a DMA Q800 TA Instruments (USA) apparatus. Samples cut into the dimensions of $40 \times 10 \times 2 \mathrm{~mm}$ were loaded with a variable sinusoidal deformation force in the single cantilever bending mode at the frequency of $1 \mathrm{~Hz}$ under the temperature rising rate of $4{ }^{\circ} \mathrm{C} / \mathrm{min}$ within the temperature range between -80 and $40{ }^{\circ} \mathrm{C}$.

Swelling degree of resulting vulcanizate $(0.2 \mathrm{~g}$ samples) was determined by equilibrium swelling in toluene (room temperature, $72 \mathrm{~h}$ ). Swelling degree was calculated in accordance with the Eq. (4):

$Q=\frac{m_{\mathrm{t}}-m_{\mathrm{o}}}{m_{\mathrm{o}}} \times 100$

where, $Q$ is swelling degree; $m_{t}$ is mass of the sample swollen after time $t(\mathrm{~g})$ and $m_{o}$ is the initial mass of sample (g).

Thermogravimetric analysis (TGA) was performed on the NETZSCH TG 209 (Germany) apparatus using 5-mg samples in the temperature range $25-600{ }^{\circ} \mathrm{C}$ and under nitrogen atmosphere, at a heating rate of $20^{\circ} \mathrm{C} / \mathrm{min}$.

\section{Results and discussion}

\section{Curing characteristics}

The influence of vulcanizing system type on the vulcanization process parameters of reclaimed rubber is shown in Table 4. The type of used accelerator and the ratio of accelerator to sulfur had no real effect on the changes of
Scheme 1 Chemical structure of used vulcanization accelerators

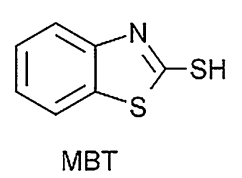

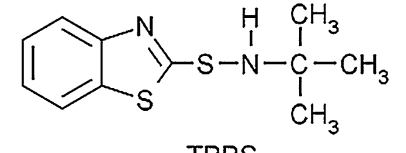

TBBS<smiles>CN(C)C(=S)SSC(=S)N(C)C</smiles>

TMTD<smiles>CN=C(Nc1ccccc1)Nc1ccccc1</smiles><smiles>c1ccc2sc(SNC3CCCCC3)nc2c1</smiles>

CBS

Table 3 Properties of used vulcanization accelerators

\begin{tabular}{lllll}
\hline Accelerator & Chemical name & Molar mass $(\mathrm{g} / \mathrm{mol})$ & Density $\left(\mathrm{g} / \mathrm{cm}^{3}\right)$ & Melting temperature $\left({ }^{\circ} \mathrm{C}\right)$ \\
\hline MBT & 2-mercaptobenzothiazole & 167.25 & 1.42 & $169-171$ \\
TBBS & $N$-tert-butyl-2-benzothiazol sulfenamide & 238.37 & 1.29 & $104-111$ \\
TMTD & tetramethylthiuram disulfide & 240.43 & 1.38 & $146-148$ \\
DPG & 1,3-diphenylguanidine & 211.29 & 1.19 & $144-146$ \\
CBS & $N$-cyclohexyl-2-benzothiazol sulfenamide & 264.42 & 1.28 & $97-105$ \\
\hline
\end{tabular}


Table 4 Curing characteristics of reclaimed rubber

\begin{tabular}{|c|c|c|c|c|c|c|c|c|}
\hline \multirow[t]{3}{*}{ Accelerator type } & \multirow[t]{3}{*}{ Accelerator/sulfur ratio } & \multicolumn{7}{|c|}{ Curing characteristics } \\
\hline & & \multicolumn{2}{|c|}{ Torque $(\mathrm{dNm})$} & \multirow[t]{2}{*}{$\Delta M(\mathrm{dNm})$} & \multirow{2}{*}{$t_{2}(\min )$} & \multirow[t]{2}{*}{$t_{90}(\min )$} & \multirow[t]{2}{*}{$\mathrm{CRI}\left(\min ^{-1}\right)$} & \multirow[t]{2}{*}{$R_{300}(\%)$} \\
\hline & & $M_{\mathrm{L}}(\mathrm{dNm})$ & $M_{\mathrm{H}}(\mathrm{dNm})$ & & & & & \\
\hline \multirow[t]{2}{*}{ MBT } & $1: 2$ & 3.5 & 33.5 & 30.0 & 1.3 & 7.0 & 17.5 & 4.8 \\
\hline & $2: 1$ & 3.9 & 20.0 & 16.1 & 1.5 & 4.3 & 35.7 & 0.6 \\
\hline \multirow[t]{2}{*}{ TBBS } & $1: 2$ & 3.8 & 41.3 & 37.5 & 3.1 & 7.6 & 22.2 & 1.7 \\
\hline & $2: 1$ & 4.0 & 36.0 & 32.0 & 3.2 & 8.2 & 20.0 & 0.2 \\
\hline \multirow[t]{2}{*}{ TMTD } & $1: 2$ & 4.0 & 51.9 & 47.9 & 1.2 & 2.9 & 58.8 & 0.4 \\
\hline & $2: 1$ & 4.8 & 53.3 & 48.5 & 1.7 & 6.8 & 19.6 & 0.0 \\
\hline \multirow[t]{2}{*}{ DPG } & $1: 2$ & 4.7 & 34.2 & 29.5 & 2.1 & 16.1 & 7.1 & 0.7 \\
\hline & $2: 1$ & 4.6 & 19.4 & 14.8 & 2.1 & 7.7 & 17.9 & 0.6 \\
\hline \multirow[t]{2}{*}{ CBS } & $1: 2$ & 3.9 & 40.3 & 36.4 & 3.2 & 7.8 & 21.7 & 0.9 \\
\hline & $2: 1$ & 3.2 & 28.8 & 25.6 & 2.8 & 5.5 & 37.0 & 0.2 \\
\hline
\end{tabular}

Table 5 Mechanical properties of revulcanized reclaimed rubber

\begin{tabular}{|c|c|c|c|c|c|c|c|c|}
\hline \multirow[t]{2}{*}{ Accelerator type } & \multirow[t]{2}{*}{ Accelerator/sulfur ratio } & \multicolumn{7}{|c|}{ Mechanical properties } \\
\hline & & $\mathrm{TS}(\mathrm{MPa})$ & $E_{\mathrm{b}}(\%)$ & $M_{50}(\mathrm{MPa})$ & $M_{100}(\mathrm{MPa})$ & $H\left({ }^{\circ} \mathrm{Sh} \mathrm{A}\right)$ & $R(\%)$ & $A\left(\mathrm{~mm}^{3}\right)$ \\
\hline \multirow[t]{2}{*}{ MBT } & $1: 2$ & $6.20 \pm 0.09$ & $182 \pm 2$ & 1.38 & 2.99 & 58 & 28 & 309 \\
\hline & $2: 1$ & $4.83 \pm 0.11$ & $250 \pm 10$ & 0.90 & 1.80 & 51 & 22 & 397 \\
\hline \multirow[t]{2}{*}{ TBBS } & $1: 2$ & $7.41 \pm 0.32$ & $152 \pm 7$ & 1.95 & 4.39 & 62 & 30 & 317 \\
\hline & $2: 1$ & $7.30 \pm 0.06$ & $178 \pm 6$ & 1.53 & 3.34 & 61 & 29 & 311 \\
\hline \multirow[t]{2}{*}{ TMTD } & $1: 2$ & $6.20 \pm 0.07$ & $98 \pm 5$ & 2.75 & - & 72 & 37 & 338 \\
\hline & $2: 1$ & $6.38 \pm 0.22$ & $104 \pm 6$ & 2.51 & 5.78 & 71 & 35 & 316 \\
\hline \multirow[t]{2}{*}{ DPG } & $1: 2$ & $6.41 \pm 0.32$ & $184 \pm 5$ & 1.42 & 2.97 & 57 & 27 & 330 \\
\hline & $2: 1$ & $4.85 \pm 0.10$ & $263 \pm 8$ & 0.83 & 1.62 & 48 & 22 & 444 \\
\hline \multirow[t]{2}{*}{ CBS } & $1: 2$ & $6.96 \pm 0.40$ & $158 \pm 6$ & 1.82 & 3.81 & 61 & 33 & 317 \\
\hline & $2: 1$ & $6.51 \pm 0.34$ & $203 \pm 14$ & 1.22 & 2.58 & 54 & 29 & 318 \\
\hline
\end{tabular}

torque minimal value $\left(M_{\mathrm{L}}\right)$, what indicates similar processing properties of investigated rubber compounds but some dependencies were observed for maximal torque $\left(M_{\mathrm{H}}\right)$ values, which correspond with stiffness and shear modulus of vulcanized samples. Independently from the accelerator/sulfur ratio, the highest value of $M_{\mathrm{H}}$ was observed for compounds vulcanized with TMTD accelerator. Their high stiffness was caused by the decreased mobility of polymer chains, what was also confirmed by the values of hardness and elongation-at-break (Table 5). Similar observations were recently presented in research work published by Ismail et al. [11] where application of conventional curing system (accelerator/sulfur ratio was 1:2) increased the values of $\Delta M$ that was corresponded with the cross-link density of vulcanizates [7]. In the case of incorporation of MBT and DPG accelerators into effective curing systems (EV) significant decrease of $\Delta M$ (cross-link density) value was observed.
The type of used accelerator evidently influenced the scorch time $\left(t_{2}\right)$, but, on the contrary, accelerator/sulfur ratio had no essential impact on this parameter. The highest values of $t_{2}$ were observed for compounds cross-linked with system based on benzothiazole sulfonamide derivatives (TBBS and CBS). Increase of the scorch time enabled safer processing of rubber compounds.

Optimum vulcanization time $\left(t_{90}\right)$ and cure rate index (CRI) of investigated materials significantly depended on the type of accelerator and the ratio of accelerator to sulfur. The lowest $t_{90}$ value $(2.9 \mathrm{~min})$ and the highest CRI value $\left(58.8 \mathrm{~min}^{-1}\right)$ were observed for rubber compound cured with conventional curing system (accelerator/sulfur 1:2) based on TMTD accelerator, while the highest $t_{90}$ (16.1 $\mathrm{min})$ and the lowest CRI values $\left(7.1 \mathrm{~min}^{-1}\right)$ were observed for compound containing DPG accelerator.

This phenomenon was due to the chemical nature of used accelerators. DPG accelerator (guanidine derivatives) 
(a)

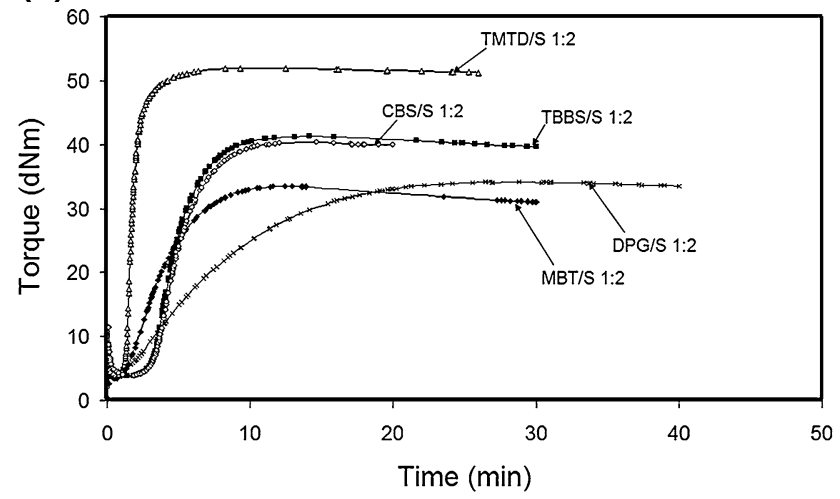

(b)

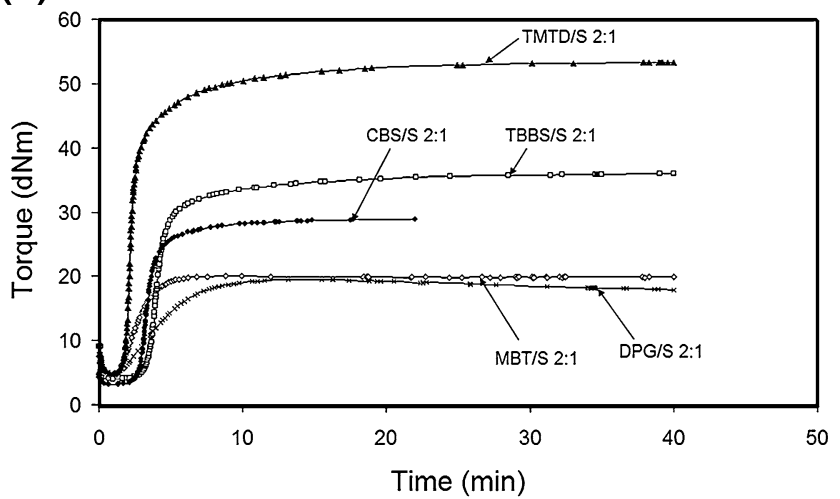

Fig. 3 Vulcametric curves of reclaimed rubber: accelerator/sulfur ratio was 1:2 (CV curing system) (a) and accelerator/sulfur ratio was 2:1 (EV curing system) (b)

is characterized by medium activity and it is usually used with other accelerators. TBBS, CBS and MBT accelerated systems provide two functions during vulcanization of rubber compounds. Firstly, they retard the vulcanization that increases the scorch time and has positive influence on safe processing of rubber compounds. Secondly, they react with zinc oxide to form sulfuric complex that accelerates polysulfidic cross-links formation [32, 33]. On the other hand, cross-linking of rubber compounds with using of TMTD containing systems strongly promotes formation of polysulfidic cross-links, which can evolve into disulfide and monosulfide cross-links.

Aging resistance of vulcanizates at elevated temperature was determined based on $R_{300}$ parameter. Irrespective of the type of used accelerator, in case of conventional curing system reversion was observed which had negative impact on the vulcanizated rubber properties. The highest reversion was noticed for MBT accelerator $\left(R_{300}=4.8 \%\right)$ and the lowest was in case of TMTD $\left(R_{300}=0.4 \%\right)$. This phenomenon may be related with thermal stability of poly-, di- and monosulfide bonds formed during curing of reclaimed rubber. For better presentation of the differences in vulcanization process, curing curves for analyzed vulcanizates are shown in Fig. 3.

\section{Static mechanical properties}

In Table 5 the influence of the type of vulcanizing system on the static mechanical properties of resulting materials is shown. Samples cured with effective system based on MBT and DPG showed the lowest values of tensile strength $(\sim 4.8 \mathrm{MPa})$ and the highest elongation-at-break $(\sim 250 \%)$. Presented results indicated weak cross-linking of these samples which was confirmed by the lowest values of $M_{50}$ and $M_{100}$ and by characteristics of vulcanization curves (the lowest values of $\Delta M$ ).

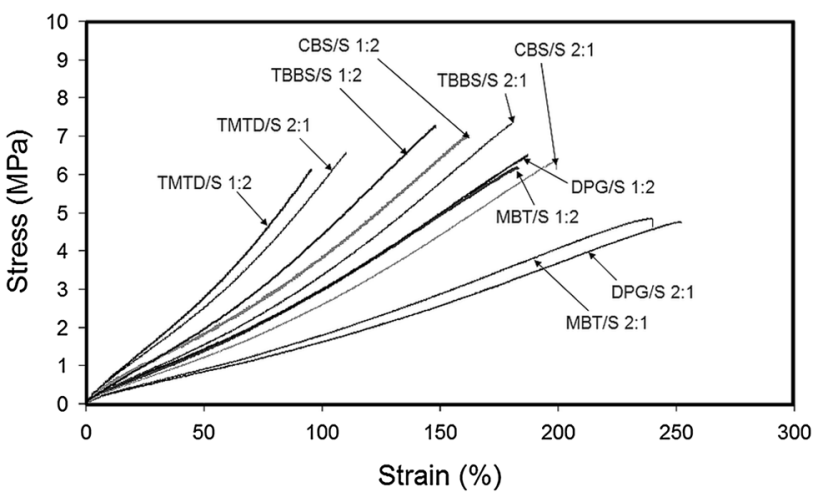

Fig. 4 Stress-stain curves for revulcanized reclaimed rubber samples (cured with MBT, TBBS and TMTD)

In case of TBBS, CBS and TMTD accelerators, the accelerator/sulfur ratio did not have significant impact on the tensile strength of resulting materials, but type of the accelerator had noticeable influence on the elongation-atbreak, which is shown in Fig. 4.

Mechanical properties values of samples cured with TMTD accelerator significantly exceeded results obtained for other accelerators. Incorporation of TMTD increased the $M_{50}$ and $M_{100}$ values, decreased the values of elongation-at-break (about ca. $50 \%$ ), increased hardness (about ca. $10^{\circ} \mathrm{Sh} \mathrm{A}$ ) and resilience (about ca. $10 \%$ increase). Presented results confirmed the decrease of elastomer chains mobility during cross-linking with TMTD which is consistent with characteristics of vulcanization (Table 4). Abrasion resistance values correspond with the results of tensile tests of obtained vulcanizates. Presented results confirm that reclaimed rubber prepared via low temperature extrusion possessed properties comparable to properties of commercial reclaimed rubbers $[34,35]$ prepared via batch methods. 
Dynamic mechanical properties

Further research was performed for the samples which showed the best mechanical properties and were vulcanized with conventional $(\mathrm{CV})$ and effective $(\mathrm{EV})$ curing systems containing MBT, TBBS and TMTD accelerators. In Fig. 5 the influence of the type of curing system on the storage modulus $\left(E^{\prime}\right)$ as a function of temperature is shown. The lowest values of $\mathrm{E}^{\prime}$ in the glassy region were observed in case of sample vulcanized with EV system MBT/S 2:1. The highest values $E^{\prime}$ in the glassy region were measured for reclaimed rubber cured with conventional system based on TMTD accelerator. The values of $\mathrm{E}^{\prime}$ modulus correspond with the stiffness and cross-link density of obtained vulcanizates.

Influence of the type of curing system on the values of loss tangent as a function of temperature and values of swelling degree as a function of time is shown in Fig. 6. Presented results were corresponded with the values of

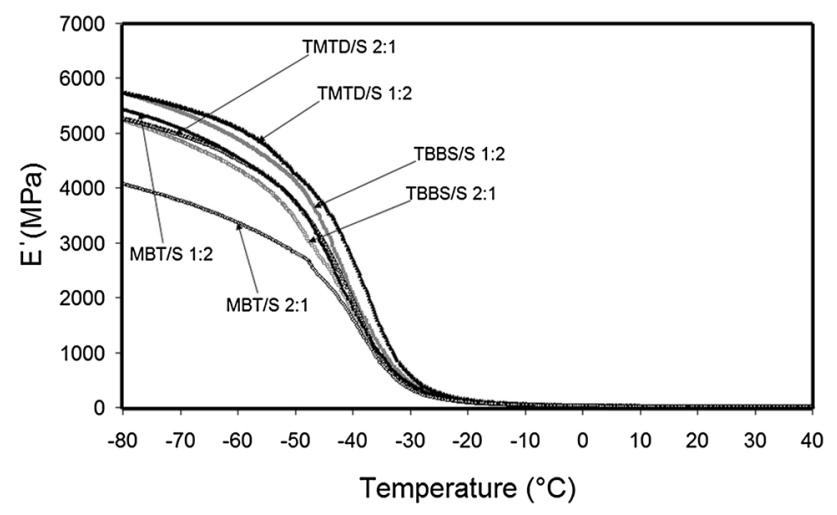

Fig. 5 Storage modulus $\left(\mathrm{E}^{\prime}\right)$ as a function of temperature determined for revulcanized reclaimed rubber samples (cured with MBT, TBBS and TMTD)

(a)

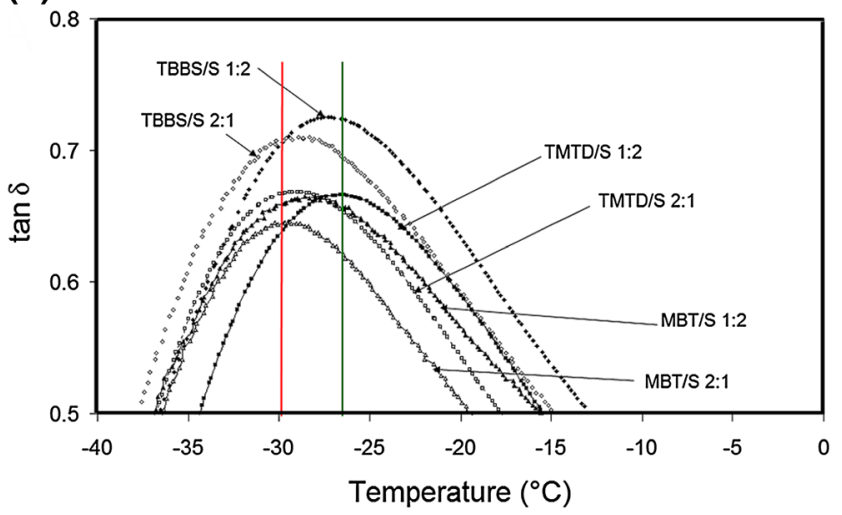

$\mathrm{E}^{\prime}$ modulus and equilibrium swelling measurements. The highest cross-link density was observed for sample cured with conventional system based on TMTD accelerator, its glass transition temperature $\left(T_{\mathrm{g}}\right)$ was $-26.6{ }^{\circ} \mathrm{C}$ and equilibrium swelling degree $\left(Q_{\text {eq. }}\right)$ was $202 \%$. For comparison, $T_{\mathrm{g}}$ and $Q_{\text {eq. }}$ for material vulcanized with EV system MBT/S 2:1 were $-29.4{ }^{\circ} \mathrm{C}$ and $283 \%$, respectively. The results of dynamic mechanical analysis were correlated with results of $\Delta M$ (curing characteristics) and static mechanical properties.

\section{TGA analysis}

In Fig. 7 results of the thermogravimetric analysis of GTR, reclaimed ground tire rubber (dGTR) and obtained vulcanizates are shown. Vulcanization of reclaimed rubber as expected enhanced the thermal stability of the resulting material, due to the increase of its cross-link density. In Fig. 7b TGA curves for the temperature range of high decomposition rate from 390 to $410{ }^{\circ} \mathrm{C}$ are shown, In comparison to GTR, lower decomposition temperature of reclaimed rubber confirms breaking of cross-link bonds during reclaiming of GTR $[36,37]$ which was confirmed by increasing of sol fraction values (see "Materials" section). Thermogravimetric curve profiles for reclaimed rubber cured with TBBS, TMTD or MTB accelerators, discussed in terms of cross-linking degree were correlated with the characteristics of vulcanization process ( $\Delta M$ values), values of swelling degree and results of static and dynamic mechanical analysis.

Presented in Fig. 8 peaks from DTG curves are related to the temperatures of maximal rate of thermal degradation of natural rubber $\left(T_{\max 1}\right)$ and styrene-butadiene rubber $\left(T_{\max 2}\right)$. These rubbers are the main compounds used in car tires manufacturing. In case of GTR and reclaimed dGTR the second peak $\left(T_{\max 2}\right)$ on DTG curve was significantly

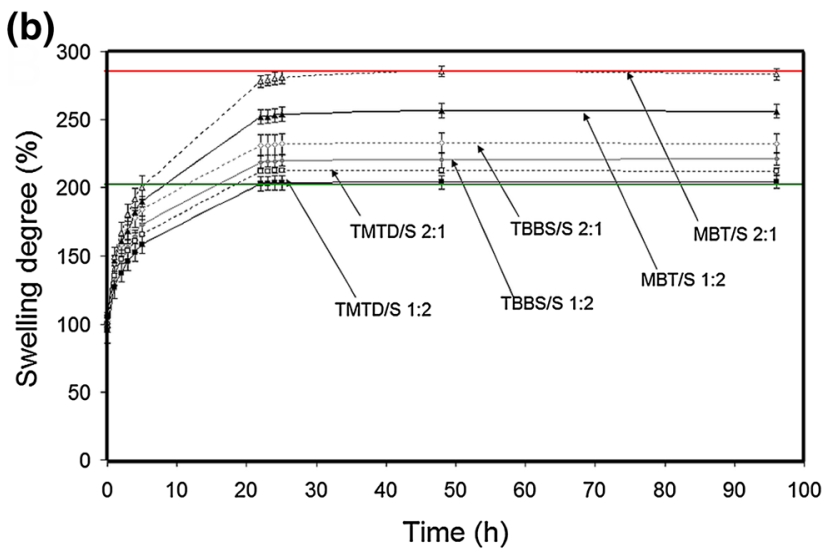

Fig. 6 Effect of vulcanizing system on: loss tangents as function of temperature (a) and swelling degree as function of time (b) determined for revulcanized reclaimed rubber (cured with MBT, TBBS and TMTD) 

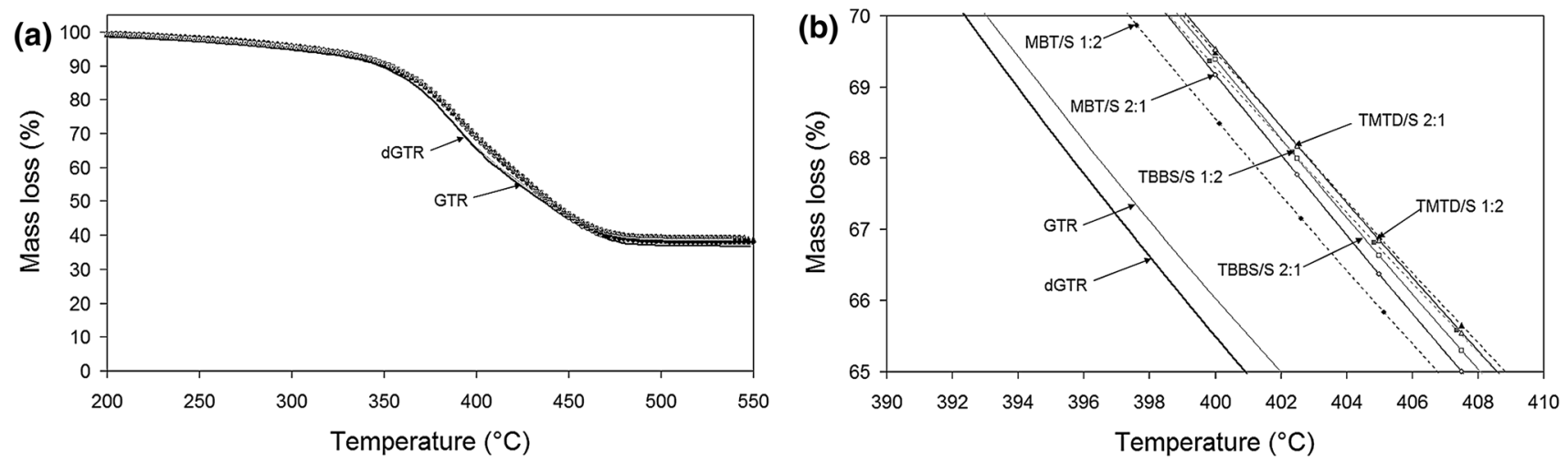

Fig. 7 TGA curves for ground tire rubber (GTR), reclaimed ground tire rubber (dGTR) and revulcanized reclaimed rubber cured with MBT, TBBS and TMTD: normal view (a) and magnification of curves for $390-410{ }^{\circ} \mathrm{C}$ temperature range (b)

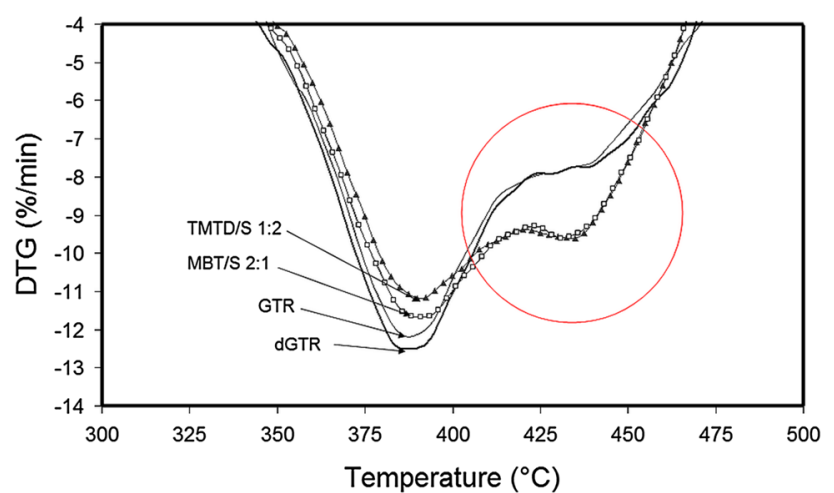

Fig. 8 DTG curves for ground tire rubber (GTR), reclaimed ground tire rubber (dGTR) and selected revulcanized reclaimed rubber samples

smaller. After vulcanization, reclaimed GTR showed increase in the peak related to the thermal decomposition of the synthetic rubber. Changes of $T_{\max 1}$ and $T_{\max 2}$ values were corresponded to the increase of the cross-link densities of NR or SBR.

\section{Conclusion}

Ground tire rubber was thermo-mechanically reclaimed using a co-rotating twin screw extruder at $120{ }^{\circ} \mathrm{C}$. Obtained reclaimed rubber was cured with different vulcanizing system. The effect of various vulcanization accelerators (MBT, TBBS, TMTD, DPG, and CBS) and two ratios of vulcanization accelerator/sulfur $(2: 1$ as conventional (CV) and 1:2 as effective (EV) systems) on curing characteristics, mechanical properties and thermal properties of reclaimed rubber were determined. The results from this work suggested that vulcanizing system type have significant influence on curing kinetics of reclaimed rubber. It was noticed that scorch time $\left(t_{2}\right)$ was evidently influenced by the type of the vulcanization accelerator, but much less by the accelerator/sulfur ratio. The highest values of $t_{2}$ were observed at applications of benzothiazole sulfonamide derivatives (TBBS and CBS). Optimum vulcanization time $\left(t_{90}\right)$, cure rate index (CRI) and reversion degree $\left(R_{300}\right)$ of investigated compounds visibly were depended on the type of used accelerator and the ratio of accelerator to sulfur. It was noticed that application of conventional curing system led to higher values of $\Delta M$, which were correlated with the cross-link density, mechanical and thermal properties of revulcanized reclaimed rubber. Revulcanized reclaimed rubber cured with conventional vulcanizing system based on TBBS and CBS accelerators possessed the best processing and mechanical properties.

This study showed that reclaimed rubber obtained by thermo-mechanical process at relatively low temperature $\left(120^{\circ} \mathrm{C}\right)$ possessed satisfactory properties for application in rubber compounds provided that it was selected a suitable vulcanizing system.

Acknowledgments The presented research was supported by the system project "InnoDoktorant-Scholarships for Ph.D. students, VIth edition" (M. Formela). This project has been co-financed by the European Union in the frame of the European Social Fund.

Open Access This article is distributed under the terms of the Creative Commons Attribution License which permits any use, distribution, and reproduction in any medium, provided the original author(s) and the source are credited.

\section{References}

1. Lo Presti D (2013) Recycled tyre rubber modified bitumens for road asphalt mixtures: A literature review. Constr Build Mater 49: 863-881 
2. Martínez JD, Puy N, Murillo R, García T, Navarro MV, Mastral AM (2013) Waste tyre pyrolysis - A review. Renew Sust Energ Rev 23:179-213

3. Karger-Kocsis J, Mészáros L, Bárány T (2013) Ground tyre rubber (GTR) in thermoplastics, thermosets, and rubbers. J Mater Sci 48:1-38

4. Diez J, Bellas R, López J, Santoro G, Marco C, Ellis G (2010) Study of the cross-link density, dynamo-mechanical behaviour and microstructure of hot and cold SBR vulcanizates. J Polym Res 17:99-107

5. Rybiński P, Janowska G (2009) Influence of network structures of nitryle rubbers on their thermal properties. Polimery 54:275-282

6. Rattanasom N, Poonsuk A, Makmoon T (2005) Effect of curing system on the mechanical properties and heat aging resistance of natural rubber/tire tread reclaimed rubber blends. Polym Test 24:728-732

7. Kim SW, Park HY, Lim JC, Jeon IR, Seo KH (2007) Cure characteristics and physical properties of ground-rubber-filled natural rubber vulcanizates: effects of the curing systems of the ground rubber and rubber matrix. J Appl Polym Sci 105:2396-2406

8. Kim SW, Hong KH, Seo KH (2003) Effects of ground rubber having different curing systems on the cross-link structures and physical properties of NR vulcanizates. Mater Res Innov 7:149-154

9. Nabil H, Ismail H, Azura AR (2014) Optimisation of accelerators and vulcanising systems on thermal stability of natural rubber/ recycled ethylene-propylene-diene monomer blends. Mater Des 53:651-661

10. Nabil H, Ismail H, Azura AR (2014) Properties of natural rubber/ recycled ethylene-propylene-diene rubber blends prepared using various vulcanizing systems. Iran Polym J 23:37-45

11. Nabil H, Ismail H, Azura AR (2014) Optimization of Accelerators on Curing Characteristics, Tensile, and Dynamic Mechanical Properties of (Natural Rubber)/(Recycled Ethylene-PropyleneDiene-Monomer) Blends. J Vinyl Addit Techn. doi:10.1002/ vnl.21358

12. Gibala D, Hamed GR (1994) Cure and mechanical behavior of rubber compounds containing ground vulcanizates. Part I: cure behavior. Rubber Chem Technol 67:636-648

13. Gibala D, Laohapisitpanich K, Thomas D, Hamed GR (1996) Cure and mechanical behavior of rubber compounds containing ground vulcanizates. Part II: Mooney viscosity. Rubber Chem Technol 69:115-119

14. Gibala D, Thomas D, Hamed GR (1999) Cure and mechanical behavior of rubber compounds containing ground vulcanizates. Part III. Tensile and tear strength. Rubber Chem Techno 72:357-360

15. Guzmán M, Agulló N, Giese U, Borrós S (2013) Exploring tire crumb as activator for sulfur vulcanization. J Appl Polym Sci 130:2809-2820

16. De D, Das A, De D, Dey B, Debnath SC, Roy BC (2006) Reclaiming of ground rubber tire (GRT) by a novel reclaiming agent. Eur Polym J 42:917-927

17. De D, De D, Singharoy GM (2007) Reclaiming of ground rubber tire by a novel reclaiming agent. I. virgin natural rubber/ reclaimed GRT vulcanizates. Polym Eng Sci 47:1091-1100

18. Sikhar BC, Subramaniam A (1996) Process for reclaiming elastomeric material. Pat. EP 0748837

19. Ishiaku US, Chong CS, Ismail H (1999) Determination of optimum De-Link R concentration in a recycled rubber compound. Polym Test 18:621-633

20. Yazdani H, Karrabi M, Ghasmi I, Azizi H, Bakhshandeh GR (2011) Devulcanization of waste tires using a twin-screw extruder: The effects of processing conditions. J Vinyl Addit Techn 17:64-69

21. Shi J, Jiang K, Ren D, Zou H, Wang Y, Lv X, Zhang L (2013) Structure and performance of reclaimed rubber obtained by different methods. J Appl Polym Sci 129:999-1007

22. Mangili I, Collina E, Anzano M, Pitea D, Lasagni M (2014) Characterization and supercritical $\mathrm{CO}_{2}$ devulcanization of cryoground tire rubber: Influence of devulcanization process on reclaimed material. Polym Degrad Stab 102:15-24

23. Lee SH, Hwang SH, Kontopoulou M, Sridhar V, Zhang ZX, Xu D, Kim JK (2009) The effect of physical treatments of waste rubber powder on the mechanical properties of the revulcanizate. $J$ Appl Polym Sci 112:3048-3056

24. Li Y, Zhao S, Wang Y (2012) Microbial desulfurization of ground tire rubber by Sphingomonas sp.: A novel technology for crumb rubber composites. J Polym Environ 20:372-380

25. Zhang XX, Lu CH, Liang M (2007) Preparation of rubber composites from ground tire rubber reinforced with waste-tire fiber through mechanical milling. J Appl Polym Sci 103:4087-4094

26. Tao G, He Q, Xia Y, Jia G, Yang H, Ma W (2013) The effect of devulcanization level on mechanical properties of reclaimed rubber by thermal-mechanical shearing devulcanization. J Appl Polym Sci 129:2598-2605

27. Maridass B, Gupta BR (2003) Recycling of waste tire rubber powder. KGK-Kaut Gummi Kunst 56:232-236

28. Formela K, Cysewska M (2014) Efficiency of thermomechanical reclaiming of ground tire rubber conducted in counter-rotating and co-rotating twin screw extruder. Polimery 59:231-238

29. Formela K, Cysewska M, Haponiuk J (2014) Thermomechanical reclaiming of ground tire rubber via extrusion at low temperature: Efficiency and limits. J Vinyl Addit Techn. doi:10.1002/vnl.21426

30. Menon ARR, Pillai CKS, Nando GB (1998) Vulcanization of natural rubber modified with cashew nut shell liquid and its phosphorylated derivative - a comparative study. Polymer 39:4033-4036

31. Khang TH, Ariff ZM (2012) Vulcanization kinetics study of natural rubber compounds having different formulation variables. $\mathrm{J}$ Therm Anal Calorim 109:1545-1553

32. Coran AY (2003) Chemistry of the vulcanization and protection of elastomers: A review of the achievements. J Appl Polym Sci 87:24-30

33. Ghosh P, Katare S, Patkar P, Caruthers JM, Venkatasubramanian V, Walker KA (2003) Sulfur vulcanization of natural rubber for benzothiazole accelerated formulations: from reaction mechanisms to a rational kinetic model. Rubber Chem Techn 76:592-693

34. Formela K, Kołacka K, Stankiewicz P, Haponiuk J, Stasiek A (2012) Effect of ground tire rubber devulcanization conditions on mechanical properties of revulcanizates. Przem Chem 91:1770-1774

35. Formela K, Cysewska M, Haponiuk J, Stasiek A (2013) The influence of feed rate and shear forces on the devulcanization process of ground tire rubber (GTR) conducted in a co-rotating twin screw extruder. Polimery 58:906-912

36. Kleps T, Piaskiewicz M, Parasiewicz W (2000) The use of thermogravimetry in the study of rubber devulcanization. J Therm Anal Calorim 60:271-277

37. Scuracchio CH, Waki DA, Da Silva MLCP (2007) Thermal analysis of ground tire rubber devulcaznized by microwaves. J Therm Anal Calorim 87:893-897 